\title{
Editorial
}

\section{Advancement in ophthalmic services in Nepal through sharing of knowledge, skills and experience}

\author{
U.F. Tegelberg, Ophthalmologist, Parkweg 9, 4461 SG, Goes, The Netherlands \\ E-mail: uftegelberg@gmail.com
}

I first came to beautiful Nepal in 1989 with a group of friends from The Netherlands to try to help out our Nepali colleagues in Nepal's need for ophthalmic assistance. We were appalled to find that the rural people of Nepal had practically no access to ophthalmic services. People were going around half-blind or towards being totally blind.

With loads of medical equipment and highly dedicated Nepalese ophthalmic assistants, we conducted eye camps (called "AankhaShibir" in Nepali) in various rural villages of Nepal. Thousands of people came to utilize our assistance, mostly for cataract problems. The results were mostly satisfactory under the grim circumstances.

The people of these areas, we learnt later, had no access to eye-problem treatment until another mobile eye-care team arrived in their village.

In the years after, there has been tremendous improvement in the country's eyecare program due to the establishment of many "Eye Hospitals and Centres". Many Nepalese ophthalmologists and ophthalmic assistants have been trained and so, many people in Nepal, both in rural and urban areas, now have relatively easy access to ophthalmic services whenever needed. Today, practically no one remains needlessly blind due to the avoidable causes irrespective of their socio-economic status in Nepal.

Times have changed for the better regarding eye-care services in Nepal, and so has technology. In the eye camps that we conducted in 1989, the preferred technique was intra-capsular cataract extraction followed by post-operative aphakic glasses. Later, we turned to extra-capsular operations with implant lenses. Then came the "manual small incision" technique and not very long after this, even the more sophisticated technique of phaco-emulsification was quite readily accessible to about half the population of Nepal.

This tremendous advance in ophthalmic treatment has been because of practical experience and the mutual sharing of medical knowledge and skills. For which, all of us in the field of ophthalmology may thank each other.

The launching of the Nepalese Journal of Ophthalmology has demonstrated the improved academic status of the Nepalese ophthalmologists and ophthalmic scientists. In the first issue of the journal (Badhu, 2009), the founder Editor-in-Chief Professor Dr Badri P Badhu stated:

"This issue of the journal is focused on translating experiences into clinical practice, stimulating ophthalmologists, particularly of the new generation, to conduct scientific research work and publishing their achievements and clinical experience. 
Such publications could be instrumental in encouraging practitioners to recognize scientific publications as an essential component of the noble philosophy of holistic and compassionate patient care with social accountability."

This journal in years past has become a strong platform for the dissemination of information amongst our professional colleagues and the world at large. I consider this opportunity of writing this short editorial an honour and I thank Prof Dr Badri Badhu and his colleagues of the Editorial Board who have always dedicated their time and energy in enlightening the ophthalmic community at large of the great progress and just as great problems of the eye care service of Nepal. Sharing knowledge of skills and experience for the betterment and improvement of the quality of life through developed and easily-accessible eye care will continue to 'brighten up' the lives of both the eye patients and the eye-care service providers.

\section{References}

Badhu B (2009). From the desk of the Editor-in-Chief. Nepal J Ophthalmol; 1(1). Retrieved from: http://www.nepjoph.org.np/pdf/NEPjOPH_20090115.pdf 